\title{
FL INSTRUCTION AND INTERACTION IN FORMAL SETTINGS
}

\author{
JERZY ZYBERT
}

Learning, including foreign languages, is a process during which an individual attempts to acquire and develop his/her knowledge and/or skills. It also involves modifying and reinforcing the learner's current knowledge and skills. The actual results of the process are attained through studying, receiving instruction, practising, and from experience. In consequence, greater knowledge and enhanced skills empower him/her to perform better in the educational environment. Learning can take various forms and can occur in a number of contexts.

Humans learn by means of

- observing (it makes imitation possible) or

- playing (it facilitates functioning in analogous circumstances), and by

- performing actual acts (it develops self-confidence in controlling events).

The learning process can be mechanical or cognitive. The former consists typically in learning by rote, which is based essentially on uncritical memorizing of information by means of its mindless repetition; in consequence, information absorbed this way allows accurate recall of material (but not its meaning); another mechanical way of learning is by means of mnemonics, i.e. techniques that help learners remember something, e.g. " 'i' before 'e' except after 'c' " for English spelling (cf. believe/deceive). The latter process consists in acquiring new knowledge meaningfully: proper understanding of new information enables the learner to relate it to the knowledge currently possessed by the individual. Therefore meaningful learning implies gaining comprehensive knowledge of the context of the facts learned. This knowledge stands in contrast to mechanically learned knowledge in which information is collected with no regard to understanding. 
The learning situation is, basically, either formal or informal; moreover, also e-learning (computer-enhanced learning) is added today to this traditional dichotomy.

With regard to foreign languages learning them is usually considered to be formal if it relates to obtaining knowledge of rules or developing a skill by study, experience, or instruction" ; it is then described as a "conscious process of accumulating knowledge of the features, such as vocabulary or grammar, of a language" (Yule 2006: 163). Consistently with this, "the accumulated knowledge" should be regarded as the consequence of the traditional practice of teaching in which a foreign language is treated as a school subject to be studied in the same fashion as other school subjects are. Foreign language learning usually takes place in a school context, characteristically within a teacher-student relationship. Qualifying the process as "formal" denotes that it is controlled and organized in relation to a particular goal or objective that students are supposed to attain. It proceeds principally through both instruction and interaction. Informal language learning is its opposite; it is not systematic, occurs typically outside the classroom and is similar to first language acquisition in a number of ways: the learner is exposed to input that is not ordered and no explicit rules are provided.

Formal language learning is a mental process during which learners obtain linguistic information from the input that they are exposed to and are expected to use in their attempts to put messages through or to communicate (i.e., interact) with others. Therefore traditional formal language teaching is a didactic process in which the teacher impinges on learners providing them with knowledge concerning foreign language rules and meanings of vocabulary thus guiding them towards developing their awareness of the new language.

More appropriately, foreign language instruction should be considered as managing or controlling the mental processes taking place in the learners' minds. The instructor enhances the development of students' communicative skills through facilitating the tasks they are given and expected to solve. This is carried out in a number of ways which can include training, tuition, coaching, and tutoring. In the process the instructor supports learners by means of techniques which make use of strategies such as demonstration, prompting, counselling, etc., and, most of all, by building up and sustaining their motivation to develop and strengthen their current language skills. The choice of techniques is made by the instructor but depends on a variety of factors, e.g., on his/her adherence to the teaching method, teaching style, personality, experience, and also on

\footnotetext{
${ }^{1}$ Although "teaching" and "instruction" are sometimes used interchangeably, instruction is not synonymous with the traditional understanding of teaching nor carried out in a similar fashion; it does not refer to transferring teacher knowledge to learners.
} 
the teaching objectives and on the students themselves: their competence level, age, size of the group, etc. The techniques actually employed by the instructor are determined by his preferred ways of assisting learners in their communicative efforts; they also serve as feedback. Moreover, they are used to prevent relapse and to strengthen learners' sense of progress and of self-mastery. Essentially though, instruction aims to increase learners' knowledge and understanding of foreign language (FL) grammar rules and of the meanings contained in the lexical and pragmatic layers of the language. Thus, instruction consists in the teacher's deliberate pedagogical activities that are intended to result in language learning. Recent interest in language teaching involves, for example, proposals related to form-focused instruction (focus-on-form) as distinct from traditional grammar teaching (focus-on formS) (cf. Dörnyei 2009: 280 ff). Results of relevant research provide rational arguments in favour of this type of instruction as it clearly enhances explicit learning.

While instruction is an activity performed by the instructor, interaction is a form of communicative exchange taking place in the classroom. Classroom interaction normally involves the teacher in discourse with his/her learner(s) or only just the learners themselves interacting with one another in groups or pairs ${ }^{2}$. Interaction is meant for students to employ the guidance obtained from instruction for immediate communicative language use. In other words, instruction is provided to develop learners' accuracy and communication skills, whereas interaction is exercised to develop fluency (and self-confidence) in their performance. Certainly, both forms of pedagogical activity normally occur together in the language classroom but they are often referred to separately in discussions concerning the actual advantages of one form over the other. The issue concerns the impact that instruction and interaction have on the ultimate outcomes of language learning/acquisition. Actually, if it were possible to show that instruction and interaction affect language learning processes directly (and also how they do) our understanding of these processes taking place in the classroom context would greatly aid and contribute to language pedagogy.

Clearly, interaction "determines what learning opportunities the learners get" (Allwright and Bailey 1991: 149). Thus it is not surprising that proficient learners profit mostly from their individual interactive experience (cf. Slimani 1987). Since classroom interaction plays a crucial role in language learning it should be obvious that it necessarily has to take place; however, it will only be efficient if it is natural and spontaneous, not enforced, and when students focus on meaning not on form.

\footnotetext{
${ }^{2}$ Three types of interaction can take place in online e-learning: student-student, studentinstructor, and student-content.
} 
Since its inception, research into SLA has attempted to find out which of the two language learning settings - naturalistic or formal - is more beneficial for the learner. Disregarding the subconscious acquisition/conscious learning controversy, available evidence indicates that learners who undergo formal instruction generally achieve better results than those who do not ${ }^{3}$ (cf. Ellis 1985; Long 1988). This contention used to be accounted for by the alleged inability of adults to approach foreign language learning otherwise than in the academic manner, i.e., for them language learning is task-learning that is based on their past learning experience. Common everyday practice and experience show that formal instruction is particularly valuable for learners at the early learning stages; knowledge developed by beginners is used very efficiently particularly in naturalistic settings in the later stages of their linguistic development. It is also known today that certain aspects of L2 cannot be learned before the learner is ready to handle relevant input data. This fact corresponds to the concept of "built-in syllabus". Moreover, available evidence suggests that rules for some grammatical structures can be internalized more easily by the learner when formal instruction focuses on them. Instruction involves providing input and may focus either on form, or on meaning, or on both. In form-focused instruction learners' conscious attention is drawn to certain specific features of the L2 forms that are being taught. In meaning-focused instruction pedagogic activities attempt to involve learners in authentic communication with the main purpose of making their messages communicatively effective and comprehensible, irrespective of grammatical accuracy. Clearly, within the communicative approach meaning-focused instruction is highly favoured while form-focused instruction is disapproved. Yet, it can be reasonably assumed that form entails meaning (cf., Long 1998). If this position is correct, form and meaning can eventually become integrated in form-focused teaching.

Interactive events (especially the verbal ones) in which learners make use of forms taught in the classroom create a great deal of learning opportunity [from exposure to input]. Of greatest advantage in this respect are various modifications of input that occur during negotiation of meaning necessary to make interaction communicatively effective. These modifications usually involve a change of form, which is carried out consciously or subconsciously by the participants. It is worth noting that modifications increase the comprehensibility of input, even though it may still contain difficult or unfamiliar words or forms. The modifications themselves carry information about the differences in form used by the learner and that provided in the feedback. As I noted elsewhere (Zybert 2003),

\footnotetext{
${ }^{3}$ This, however, is only true of adult learners and does not obtain for children, who can acquire L2 in a very short time if immersed in an L2 community.

${ }^{4}$ Pienemann's (1985) "teachability hypothesis" seems particularly valid in this case.
} 
attention to form strengthens the learner's linking of form and meaning. Attention to form, especially when occurring coincidentally, is often activated by communicative problems faced by learners during verbal interaction. It ultimately enhances language leaning - it is often the case that what emerges unexpectedly during a language class is more learnable than what has been carefully planned for the lesson. An incidental and/or totally unpredicted occurrence of a given form draws the learner's attention just because of its novelty or due to its unexpected or striking appearance, coming as a surprise. Attention attracted this way is, undoubtedly, selective but, nevertheless, may be particularly useful for highlighting (and learning) L1-L2 contrasts.

Actually, this does not necessarily relate to all students. With regard to their attention to form and depending on their involvement in the learning process teachers differentiate at least three types: indifferent, collaborative, and autonomous. Their attention and involvement is particularly noticeable in their response to the feedback provided during class interaction. Students in the first group are actually inattentive and uninterested in developing their language skills. They are either totally unconcerned with appropriate form and ignore correction or accept being corrected without much desire for improvement. Collaborative students are willing to participate in interactive acts, value proper forms and highly appreciate correction, especially if it is personal and performed by the teacher; yet, they reject peer correction. These students are concerned with both accuracy and fluency. Autonomous students are very eager to interact - they are usually high risk-takers and wish to check if the forms they use are correct and appropriate. Being self-directed they give heed to self-correction and derive lots of satisfaction from solving problems by themselves.

Instruction that consists in mere providing rules and explaining their function and then demanding that learners recite them, as used to be the case in times past (and still is here and there), has been proved futile (cf. Allwright 1984). It is suggested here that the type of instruction that is the most beneficial in the learning process is that which results in learners' arriving at understanding the meanings and functions of various bits of FL through their own discovery and problem-solving efforts. The instructor's major role is thus helping learners to reduce their learning effort. One way of doing this is creating a challenging learning situation which can be established in the language class by prompting, hinting, and guiding learners instead of giving them ready answers or solutions. In a sense the situation corresponds to Krashen's Input Hypothesis (1982), according to which language learners are able to comprehend and subconsciously acquire some new lower-level rules and some lexical items, given they make effortful discovery based on their current knowledge level. On the other hand, the favourable learning situation can also be compared to Vygotsky's Zone of 
Proximal Development (1978), which refers to the disparity between what the child can do alone and what he is capable of doing with appropriate assistance from others, which serves as a "scaffolding". Actually, the concept relates to the child's cognitive development but may, nevertheless, be extended to explaining/understanding the FL teaching/learning processes. Since these processes take place in a social situation the teacher should guarantee his students a safe environment in which they are encouraged to try doing their best, are given sufficient time to use language, and are helped in their efforts. This situation affects the ZDF in that it diminishes "the distance between the actual developmental levels as determined by independent problem solving and the level of potential development as determined through problem solving under adults' guidance or in collaboration with more capable peers" (Mellen Day 2002: 3).

Voices in favour of focusing on instruction or on interaction can only be validated if sufficient research findings support the postulated claims. The following research is a modest attempt to shed some light on the instruction/interaction controversy with regard to the superiority of one form of didactic activity over the other. It was designed and conducted among Polish school learners of English. Seventy students were carefully selected to participate in an experiment; they were divided into four groups (A through $\mathrm{D}$ ) according to their age and proficiency as follows: A (16 students) and B (18 students) - all 12 years old, C (19 students) and D (17 students) - 16 years old. They were approximately of the same proficiency level having had three and a half years of instruction in the English language at school. Their level was assessed on the basis of the results of the proficiency test they had taken before the experiment started. Apart from the age factor the fundamental difference between the groups was the didactic approach adopted by their teachers during the experiment. The teachers agreed to strictly abide by the requirements of the experiment: the teachers of the students in groups $\mathrm{A}$ and $\mathrm{C}$ focused on the teaching that aimed at accuracy; the teachers of the students in groups B and D focused on interaction and aimed at fluency. In accordance with the discussion on instruction and interaction in the earlier part of this paper, the teaching/learning activities were designed and practised to develop accuracy or fluency in the respective groups. The experiment lasted for three months during which all four groups had 37 one-hour English classes with their instructors. During this period the researcher visited each group five times without any prior notice and measured the instruction and interaction time meticulously to assure equal distribution of time devoted to instruction and interaction in each group. After the experiment an achievement test was administered to the students and the scores gained by individual students and the groups were analyzed and compared for differences. The results of the test are presented in the table below: 


\begin{tabular}{|c|c|c|c|}
\hline Group & Mean & Highest & Lowest \\
\hline A & 38 & 47 & 32 \\
\hline B & 43 & 45 & 30 \\
\hline C & 47 & 74 & 43 \\
\hline D & 63 & 91 & 52 \\
\hline
\end{tabular}

Of interest and worth noting are the differences between the highest and lowest scores obtained in particular groups: in A and B the difference is exactly the same: 15\%; however, in $\mathrm{C}$ the gap is wider: $31 \%$, and in $\mathrm{D}$ the widest: just over $51 \%$. If the interpretation of the results is correct, the scores suggest that in the case of 12-year-olds it does not really matter for achievement whether the teaching focuses on accuracy or fluency; however, it does with 16-year-olds: not only the differences between the highest and the lowest scores are greater, but the divergence between the mean scores is significant. The conclusion that follows from it is that of the two adolescent groups of students the older ones benefit from teaching that focuses on interaction, not on accuracy.

It has to be stressed that the results presented above do not settle - and indeed do not aspire to settle - the dispute under discussion.

\section{References}

Allwright, R. 1984. "Why don't learners learn what teachers teach? - The interaction hypothesis". In: Singleton, D. and D. Little. (eds.). Language learning in formal and informal contexts. Dublin: IRAAL. 3-18

Allwright, D. and K. Bailey. 1991. Focus on the language classroom. Cambridge: Cambridge University Press.

Dörnyei, Z. 2009. The psychology of second language acquisition. Oxford: Oxford University Press.

Ellis, R. 1985. Understanding second language acquisition. Oxford: Oxford University Press.

Ellis, R. 1990. Instructed second language acquisition: learning in the classroom. Oxford: Blackwell.

Long, M. 1988. "Instructed interlanguage development". In: Beebe, L. (ed.). Issues in second language acquisition: multiple perspectives. Rowley, Mass.: Newbury House.

Mellen Day, E. 2002. Identity and the young English language learner. Clevedon: Multilingual Matters.

Slimani, A. 1987. The teaching/learning relationship: learning opportunities and the problem of uptake - an Algerian case study. Unpublished Ph.D. dissertation, University of Lancaster.

Vygotsky, L. 1978. Mind in society. Cambridge, Mass.: The MIT Press.

Yule, G. 2006 (3rd edition). The study of language. Cambridge: Cambridge University Press.

Zybert, J. (2003). "Form in learning foreign lexis". Studia Anglica Posnaniensia 39. 233-246. 